\title{
Article \\ The Effect of Surgical Mask Use in Anaerobic Running Performance
}

\author{
José Francisco Tornero-Aguilera ${ }^{1} \mathbb{1}$, Alejandro Rubio-Zarapuz ${ }^{1}$, Alvaro Bustamante-Sánchez ${ }^{1}(\mathbb{D}$ \\ and Vicente Javier Clemente-Suárez ${ }^{1,2, *(\mathbb{D})}$ \\ 1 Faculty of Sports Sciences, Universidad Europea de Madrid, Tajo Street, s/n, 28670 Madrid, Spain; \\ josefranciso.tornero@universidadeuropea.es (J.F.T.-A.); alejandro.rubio.z@hotmail.com (A.R.-Z.); \\ alvaro.bustamante@universidadeuropea.es (A.B.-S.) \\ 2 Grupo de Investigación en Cultura, Educación y Sociedad, Universidad de la Costa, \\ Barranquilla 080002, Colombia \\ * Correspondence: vctxente@yahoo.es; Tel.: +34-902-232-350; Fax: +34-911-413-585
}

check for updates

Citation: Tornero-Aguilera, J.F.; Rubio-Zarapuz, A.; BustamanteSánchez, A.; Clemente-Suárez, V.J. The Effect of Surgical Mask Use in Anaerobic Running Performance. Appl. Sci. 2021, 11, 6555. https:// doi.org/10.3390/app11146555

Academic Editor: Redha Taiar

Received: 17 June 2021

Accepted: 14 July 2021

Published: 16 July 2021

Publisher's Note: MDPI stays neutral with regard to jurisdictional claims in published maps and institutional affiliations.

Copyright: (c) 2021 by the authors. Licensee MDPI, Basel, Switzerland. This article is an open access article distributed under the terms and conditions of the Creative Commons Attribution (CC BY) license (https:// creativecommons.org/licenses/by/ $4.0 /)$.

\begin{abstract}
COVID-19 restrictions stipulate the mandatory use of surgical masks during outdoor and indoor physical activities. The impact of this on athletic performance and especially on anaerobic physical activities is poorly known. The aim of the present research was to analyze the effect of surgical mask use on the anaerobic running performance of athletes. Modifications in running time, blood lactate, blood glucose, blood oxygen saturation, subjective perceived stress, rating of perceived exertion, and heart rate variability were measured in $50 \mathrm{~m}$ and $400 \mathrm{~m}$ maximal running tests with and without the use of surgical masks in 72 athletes. The use of a surgical mask increased blood lactate concentration, sympathetic autonomic modulation, perceived exertion, perceived stress, and decreased blood oxygen saturation in 50 and $400 \mathrm{~m}$ running tests. Thus, the higher levels of blood lactate and lower blood oxygen saturation require adaptation of the athlete's rest and recovery periods to the acute workload. The higher level of sympathetic activation makes the acute and chronic control of autonomic modulation essential for an efficient training periodization. Finally, the use of acid buffers such as bicarbonate or sodium citrate would be a recommended ergogenic strategy.
\end{abstract}

Keywords: COVID-19; blood oxygen saturation; rating of perceived exertion; glucose; sport performance

\section{Introduction}

COVID-19 is an infectious disease caused by the severe acute respiratory syndrome coronavirus (SARS-CoV-2), the rapid spread and contagiousness of which has led to the COVID-19 pandemic [1]. Governments have been forced to adopt containment measures to control its spread and to prevent healthcare systems from collapsing. Thus, restrictive and limiting measures were taken in public spaces, such as the mandatory use of face masks. This policy was extended to sports practice due to the impossibility of maintaining social distance, and while exercising either outdoors and indoors due to increased respiratory volume and greater risk of contagiousness [2]. Authors relate that one of the populations that could suffer more from the consequences and restrictions of COVID-19 are athletes, especially professional ones [3]. Their daily routines are in conflict with the limitations and restrictions, which could be a cause of loss of performance and adaptations, limiting the acquisition of new abilities and performance improvements [4]. Athletes already perceive COVID-19 to be having a negative effect on their physical activity profile [5]. Some authors suggest interventions to improve psychological flexibility and coping to reach an optimal and adaptive psychophysiological status $[4,6]$.

Regarding masks, there is a large controversy around their use while exercising, especially among athletes. Authors suggest that wearing a mask forms a closed circuit of inspired and expired air, which induces a hypercapnic environment due to inadequate oxygen supply and rebinding of carbon dioxide [7]. Thus, producing an acidic environment 
both at the alveolar and blood vessel levels, leading to physiological alterations [8] and symptoms such as fatigue, discomfort, dizziness, headache, shortness of breath, muscular weakness, and drowsiness [9]. This situation may lead to decreased hemoglobin saturation due to the to increased $\mathrm{CO}_{2}$ partial pressure, and increase aortic pressure and left ventricular pressure, leading to an upsurge of cardiac overload and coronary demand [10] capable of directly affecting sports performance. However, other authors suggest no impact on exercise capacity and performance [11], even while wearing a FPP2/N95 mask. Furthermore, a recent review suggested that wearing face masks while exercising has only small effects on physiological responses and no effect on exercise performance [12]. In line with this, authors showed that a $1 \mathrm{~h}$ treadmill walk at $50-60 \%$ of maximal workload predicted maximal heart rate [13] $(5.6 \mathrm{~km} / \mathrm{h}, 0 \%$ grade) [14]; 30 min steady-state cycling at $50 \%$ of maximal workload [15], 10 min walk on a treadmill [16], or a 6 min treadmill walk $(4 \mathrm{~km} / \mathrm{h}$, $10 \%$ grade) [17] while wearing a mask have no effects on performance. However, these studies suggesting non-impaired physical performance focus on a healthy population and medium to light physical activity, but high intensity activity is not considered.

Thus, information about the effect of mask use in high intensity physical activities is still poorly known. For this reason, we proposed the present research with the aim of analyzing the effect of surgical mask use on the anaerobic running performance of athletes. The initial hypothesis was that there would be a decrease of anaerobic running performance wearing a surgical mask.

\section{Material and Methods}

\subsection{Participants}

We analyzed 72 recreational athletes ( 27 women, 45 men, $28.1 \pm 5.8$ years, $169.3 \pm 9.4 \mathrm{~cm}$, $70.7 \pm 10.1 \mathrm{~kg}, 7.0 \pm 3.2$ years of training in athletics club). The research procedure was done following the Declaration of Helsinki (revised in Brazil, 2013) and approved by the Ethics Committee of the University (CIPI/18/074). Before starting the study, all participants were informed about the process to be carried out and gave their voluntary written informed consent.

\subsection{Procedure}

To reach the study aim, participants performed two anerobic running tests $(50 \mathrm{~m}$ and $400 \mathrm{~m}$ ) in an outdoor running track field with and without surgical mask, between 8:30 a.m. and 10.50 a.m., temperature of $22.1 \pm 0.5^{\circ} \mathrm{C}$, and $40.2 \pm 2.3 \%$ of humidity, in two different days separated by $48 \mathrm{~h}$. The inclusion criteria were membership in an athletic club, a minimum of five years of training and experience, and negative PCR result one week before testing. The exclusion criteria were use of ergogenic aids, use of any other nonsurgical mask, injury in the last 3 months, presence of COVID-19 symptomatology/positive in the last 4 months, presence of COVID-19 symptomatology during the week of the test, or direct contact with a positive case. Participants were then randomly divided into two groups, the first group conducted the first evaluation day of the test with mask and the second evaluation day without the mask. The other group conducted the first evaluation day without mask and the second evaluation day with the mask. In both days, participants provided a basal sample, then began a standardized warm up consisted of $5 \mathrm{~min}$ of running (light aerobic), joint mobility of the main joint axes, ballistic stretching, and 5 speed progressions as reported in previous research [18]. Then, they conducted a $50 \mathrm{~m}$ sprint test at maximum intensity and after $20 \mathrm{~min}$ of recovery performed a $400 \mathrm{~m}$ test at maximum intensity. These two tests are both considered anaerobic, excellent tests of this metabolic pathway. The $50 \mathrm{~m}$ is an eminently anaerobic alactic test, while $400 \mathrm{~m}$ is a lactic acid power test.

Before and after tests the following parameters were evaluated [18]:

- Body height and weight by a SECA model 714 following previous procedures [19].

- Rating of perceived exertion by the Borg Scale (6-20) [20].

- Subjective Perceived Stress (0-100) [21] as in previous psychophysiological research. 
- Blood oxygen saturation by an oximeter OXYM4000 (Quirumed, Madrid, Spain), placed in the index finger of the right arm.

- Blood glucose concentration by the analysis of $5 \mu \mathrm{L}$ of capillary finger blood using a portable analyzer (One Touch Basic, LifeScan Inc., Madrid, Spain).

- Heart Rate (HR) and Heart Rate Variability (HRV) was recorded by Polar Team Pro Sensor, Polar Electro, Kempele, Finland) during the $15 \mathrm{~min}$ prior to warming up and during the athletic tests, following the procedures of previous research [22]. The Polar system has a sampling frequency of $1000 \mathrm{~Hz}$ and is able to register the RR intervals (time interval between $\mathrm{R}$ waves of the electrocardiogram) for the analysis of HRV and the number of beats per minute for the HR analysis. The HRV data collected was analyzed by the Kubios HRV v2.2 software program (University of Kuopio, Kuopio, Finland) with no correction factor, since the measurements obtained were clean and free of noise. The following HRV variables were analyzed [23]:

- Time-Domain. RMSSD (root mean square of successive differences between normal heartbeats, which reflects the beat-to-beat variance in HR and is the primary timedomain measure used to estimate the vagally mediated changes reflected in HRV), PNN50\% (the percentage of adjacent NN intervals that differ from each other by more than $50 \mathrm{~m}$, closely correlated with PNS activity) and SDNN (the standard deviation of the average normal-to-normal (NN) intervals for each of the $5 \mathrm{~min}$ segments) were analyzed.

- Frequency-Domain (Spectral Measures) Analysis. We analyzed the low-frequency (LF) and high-frequency (HF) power components in normalized units (n.u). The frequency ranges where, HF: $0.15-0.40 \mathrm{~Hz}$ and LF: $0.04-0.15 \mathrm{~Hz}$.

- Nonlinear domain analysis. SD1 and SD2 were measured to reflect the fluctuations of the HRV via a Poincare chart, physiologically, on the transverse axis. SD1 reflects parasympathetic activity while SD2 reflect the long-term changes of RR intervals and is considered an inverse indicator of sympathetic activity.

\subsection{Statistical Analysis}

The SPSS statistical package (version 21.0; SPSS, Inc., Chicago, IL, USA) was used to analyze the data. Normality assumptions were checked with a Kolmogorov-Smirnov test. A two-factor mixed ANOVA test was used to compare the effect of the test (basal, $50 \mathrm{~m}, 400 \mathrm{~m}$ ), the effect of wearing a surgical mask, and the interaction between the type of test and the effect of wearing a surgical mask, together with a Bonferroni post hoc test to analyze comparisons pairwise. The level of significance for all the comparisons was set at $p \leq 0.05$.

\section{Results}

The results are reported with their mean and standard deviation. Table 1 shows the results of psychophysiological results of tests. There was a significant effect of surgical masks in the performance of tests. Participants not wearing surgical masks had better time $(p<0.05)$ in both tests $(8.55 \mathrm{~s}$ vs. $9.62 \mathrm{~s}$ in $50 \mathrm{~m}, 74.9 \mathrm{~s}$ vs. $79.4 \mathrm{~s}$ in $400 \mathrm{~m})$. There was a significant effect of surgical masks on glucose and blood lactate levels. Participants not wearing a surgical mask had lower values of glucose $(p<0.05)(92.8 \mathrm{mg} / \mathrm{dL}$ vs. $106.0 \mathrm{mg} / \mathrm{dL})$ and blood lactate $(8.96 \mathrm{mmol} / \mathrm{L}$ vs. $13.0 \mathrm{mmol} / \mathrm{L})$ at the $400 \mathrm{~m}$ test. There was a significant effect of surgical mask wearing on the rating of perceived exertion (RPE). Participants not wearing surgical masks had lower values of RPE $(p<0.05)$ at the $400 \mathrm{~m}$ test (17.5 vs. 18.7). There was a significant effect of surgical masks on the blood oxygen saturation (BOS) in all tests. Participants not wearing surgical masks had higher values of BOS $(p<0.05)$ at the $50 \mathrm{~m}$ test $(97.8 \%$ vs. $95.2 \%)$, and $400 \mathrm{~m}$ test $(98.1 \%$ vs. $96.7 \%)$. In general, there were higher means of stress, RPE and HR at the $400 \mathrm{~m}$ vs. $50 \mathrm{~m}$ and basal, and between $50 \mathrm{~m}$ and basal too. 
Table 1. Psychophysiological modifications in the $50 \mathrm{~m}$ and $400 \mathrm{~m}$ tests with and without mask.

\begin{tabular}{|c|c|c|c|c|c|c|c|c|c|c|c|c|c|c|c|}
\hline & \multicolumn{4}{|c|}{ Basal Test } & \multicolumn{4}{|c|}{$50 \mathrm{~m}$ Test } & \multicolumn{4}{|c|}{$400 \mathrm{~m}$ Test } & \multirow{2}{*}{\multicolumn{3}{|c|}{ Mask and Test Effect }} \\
\hline & \multicolumn{2}{|c|}{ No Mask } & \multicolumn{2}{|c|}{ Mask } & \multicolumn{2}{|c|}{ No Mask } & \multicolumn{2}{|c|}{ Mask } & \multicolumn{2}{|c|}{ No Mask } & \multicolumn{2}{|c|}{ Mask } & & & \\
\hline & $\mathbf{M}$ & SD & $\mathbf{M}$ & SD & $\mathbf{M}$ & SD & $\mathbf{M}$ & SD & $\mathbf{M}$ & SD & $\mathbf{M}$ & SD & $\mathbf{F}$ & $p$ & $\eta^{2}$ \\
\hline Time (s) & N/A & N/A & N/A & $\mathrm{N} / \mathrm{A}$ & $\begin{array}{c}8.55 \\
* \text { ，㧊 }\end{array}$ & 0.84 & $\begin{array}{c}9.62 \\
* \text { ，㧊 }\end{array}$ & 1.76 & 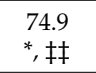 & 9.38 & $\begin{array}{l}89.2 \\
* \text { ，㧊 } \\
\end{array}$ & 13.9 & 2.582 & 0.011 & 0.025 \\
\hline $\begin{array}{l}\text { Lactate } \\
(\mathrm{mmol} / \mathrm{L})\end{array}$ & $\mathrm{N} / \mathrm{A}$ & N/A & N/A & $\mathrm{N} / \mathrm{A}$ & $\begin{array}{l}5.12 \\
\ddagger \ddagger \ddagger\end{array}$ & 2.74 & $\begin{array}{l}5.88 \\
\text { 㧊 }\end{array}$ & 3.70 & 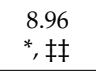 & 3.38 & $\begin{array}{l}13.0 \\
*, \neq \ddagger\end{array}$ & 4.98 & 0.941 & 0.034 & 0.008 \\
\hline $\begin{array}{l}\text { Glucose } \\
(\mathrm{mg} / \mathrm{dL})\end{array}$ & 97.5 & 9.42 & $\begin{array}{c}95.7 \\
\ddagger \ddagger\end{array}$ & 8.36 & 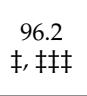 & 20.3 & $\begin{array}{c}93.6 \\
\ddagger \text {, 㧊 }\end{array}$ & 22.5 & $\begin{array}{l}92.8 \\
*, \neq \\
\text { 拉 }\end{array}$ & 16.95 & $\begin{array}{c}106.0 \\
* \text {, } \\
\ddagger \ddagger\end{array}$ & 21.6 & 19.001 & 0.000 & 0.136 \\
\hline $\begin{array}{l}\mathrm{RPE}(0-20 \\
\text { rank) }\end{array}$ & $\begin{array}{l}7.57 \\
\ddagger \ddagger \\
\text { 采 }\end{array}$ & 1.24 & $\begin{array}{c}7.85 \\
\ddagger \ddagger \\
\text { 拉 }\end{array}$ & 2.00 & $\begin{array}{c}13.7 \\
\ddagger ， \ddagger \ddagger \ddagger\end{array}$ & 3.75 & $\begin{array}{c}13.4 \\
\ddagger ， \text { 㧊 }\end{array}$ & 2.9 & $\begin{array}{c}17.5 \\
*, \ddagger, \ddagger \ddagger\end{array}$ & 1.82 & $\begin{array}{c}18.7 \\
*, \ddagger, \ddagger \ddagger\end{array}$ & 1.65 & 3.117 & 0.045 & 0.050 \\
\hline $\begin{array}{l}\text { SPS }(0-100 \\
\text { rank) }\end{array}$ & $\begin{array}{c}28.1 \\
\ddagger \ddagger \\
\ddagger \ddagger \ddagger\end{array}$ & 20.7 & $\begin{array}{c}21.9 \\
\text { 衣 } \\
\text { 㧊 }\end{array}$ & 22.8 & $\begin{array}{c}37.0 \\
\ddagger, \ddagger \ddagger \ddagger\end{array}$ & 25.7 & $\begin{array}{c}36.7 \\
\ddagger ， \ddagger \ddagger\end{array}$ & 24.5 & $\begin{array}{c}52.1 \\
\ddagger, \ddagger \ddagger\end{array}$ & 6.1 & $\begin{array}{c}61.6 \\
*, \ddagger, \ddagger \ddagger\end{array}$ & 9.42 & 0.587 & 0.036 & 0.005 \\
\hline HR (bpm) & $\begin{array}{c}70.8 \\
\ddagger \ddagger \\
\text { 拉 }\end{array}$ & 15.5 & $\begin{array}{c}72.0 \\
\ddagger \ddagger \\
\ddagger \ddagger \ddagger\end{array}$ & 11.8 & $\begin{array}{c}106.3 \\
\ddagger\end{array}$ & 35.3 & $\begin{array}{c}110.6 \\
\ddagger\end{array}$ & 35.1 & $\begin{array}{c}152.4 \\
\ddagger\end{array}$ & 15.9 & $\begin{array}{c}167.6 \\
\ddagger\end{array}$ & 25.92 & 0.093 & 0.911 & 0.001 \\
\hline BOS (\%) & 97.5 & 0.97 & $\begin{array}{c}97.8 \\
\ddagger \ddagger \\
\text { 拉 }\end{array}$ & 0.78 & $\begin{array}{c}97.8 \\
*\end{array}$ & 1.49 & $\begin{array}{l}95.2 \\
*, \neq \\
\neq \neq \ddagger\end{array}$ & 6.02 & $\begin{array}{c}98.1 \\
*\end{array}$ & 1.31 & $\begin{array}{c}96.7 \\
*, \ddagger, \ddagger \ddagger\end{array}$ & 3.06 & 7.397 & 0.003 & 0.059 \\
\hline
\end{tabular}

M: Mean. SD: Standard Deviation. F: Fisher-Snedecor test. $\eta^{2}$ : Partial eta squared. N/A: Not available. RPE: Rate of Perceived Exertion. SPS: Subjective Perceived Stress. HR: Heart Rate. BOS: Blood Oxygen Saturation. HGS: Handgrip Strength. $\ddagger$ Difference with basal test $(p<0.05)$. 㧊 Difference with $50 \mathrm{~m}$ test $(p<0.05)$. 抽 Difference with $400 \mathrm{~m}$ test $(p<0.05) .{ }^{*}$ Differences between no mask/mask groups $(p<0.05)$.

Table 2 shows the results of HRV for each test. There was a significant effect of surgical masks in RMSSD values. Participants not wearing surgical masks had lower values $(p<0.05)$ at the $50 \mathrm{~m}$ test $(9.72 \mathrm{~ms}$ vs. $21.2 \mathrm{~ms})$. There was a significant effect of surgical masks on pNN50 values. Participants not wearing surgical masks had lower values $(p<0.05)$ at the $400 \mathrm{~m}$ test $(0.00 \%$ vs. $0.32 \%)$. There was a significant effect of surgical masks on SD1 values. Participants not wearing surgical masks had lower values $(p<0.05)$ at the $50 \mathrm{~m}$ test $(6.89 \mathrm{~ms}$ vs $9.02 \mathrm{~ms})$. There was a significant effect of surgical masks on HF values. Participants not wearing surgical masks had higher values $(p<0.05)$ at the basal test (29.7 vs. 21.4). If we take time domain HRV measurements by group, values are usually higher in basal vs. $50 \mathrm{~m}$ and $400 \mathrm{~m}$ tests, and in $50 \mathrm{~m}$ and $400 \mathrm{~m}$ test. The opposite happens if frequency domain values are observed, usually being higher in $400 \mathrm{~m}$ vs. $50 \mathrm{~m}$ and basal, and in $50 \mathrm{~m}$ vs basal test.

Table 2. Heart rate variability modifications in the $50 \mathrm{~m}$ and $400 \mathrm{~m}$ tests with and without mask.

\begin{tabular}{|c|c|c|c|c|c|c|c|c|c|c|c|c|c|c|c|}
\hline & \multicolumn{4}{|c|}{ Basal Test } & \multicolumn{4}{|c|}{$50 \mathrm{~m}$ Test } & \multicolumn{4}{|c|}{$400 \mathrm{~m}$ Test } & \multirow{2}{*}{\multicolumn{3}{|c|}{ Mask and Test Effect }} \\
\hline & \multicolumn{2}{|c|}{ No Mask } & \multicolumn{2}{|c|}{ Mask } & \multicolumn{2}{|c|}{ No Mask } & \multicolumn{2}{|c|}{ Mask } & \multicolumn{2}{|c|}{ No Mask } & \multicolumn{2}{|c|}{ Mask } & & & \\
\hline & $\mathbf{M}$ & SD & $\mathbf{M}$ & SD & $\mathbf{M}$ & SD & $\mathbf{M}$ & SD & $\mathbf{M}$ & SD & $\mathbf{M}$ & SD & F & $p$ & $\eta^{2}$ \\
\hline $\begin{array}{l}\text { SDNN } \\
(\mathrm{ms})\end{array}$ & $\begin{array}{c}32.5 \\
\ddagger \ddagger \\
\ddagger \ddagger \ddagger\end{array}$ & 10.6 & 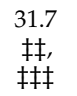 & 7.16 & $\begin{array}{l}24.27 \\
\ddagger \text { 㧊 }\end{array}$ & 16.2 & $\begin{array}{c}31.7 \\
\ddagger ， \ddagger \ddagger \ddagger\end{array}$ & 7.16 & $\begin{array}{l}8.86 \\
\ddagger \text {, } \ddagger\end{array}$ & 5.70 & $\begin{array}{l}12.8 \\
\ddagger\end{array}$ & 24.0 & 1.574 & 0.211 & 0.013 \\
\hline $\begin{array}{l}\text { RMSSD } \\
(\mathrm{ms})\end{array}$ & $\begin{array}{c}23.0 \\
\ddagger \ddagger \\
\ddagger \ddagger \ddagger\end{array}$ & 6.37 & $\begin{array}{c}21.2 \\
\ddagger \ddagger \\
\text { 㧊 }\end{array}$ & 6.02 & $\begin{array}{l}21.2 \\
*, \neq \\
\ddagger \neq \ddagger\end{array}$ & 6.39 & $\begin{array}{l}9.72 \\
*, \ddagger\end{array}$ & 6.02 & 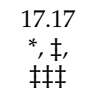 & 2.59 & $\begin{array}{l}8.20 \\
\ddagger \text {, } \ddagger\end{array}$ & 5.19 & 4.716 & 0.010 & 0.038 \\
\hline pNN50 (\%) & $\begin{array}{c}4.29 \\
\ddagger \ddagger \\
\ddagger \neq \ddagger\end{array}$ & 3.14 & $\begin{array}{c}3.78 \\
\ddagger \ddagger \\
\text { 拉 }\end{array}$ & 3.52 & $\begin{array}{c}0.60 \\
\ddagger \text { 㧊 }\end{array}$ & 1.52 & $\begin{array}{c}1.12 \\
\ddagger \text { 㧊 }\end{array}$ & 1.79 & $\begin{array}{c}0.00 \\
*, \ddagger, \neq \ddagger\end{array}$ & 0.00 & $\begin{array}{c}0.32 \\
*, \ddagger, \neq \ddagger\end{array}$ & 1.01 & 1.815 & 0.176 & 0.015 \\
\hline LF (n.u.) & $\begin{array}{c}70.4 \\
\text { *, 年 } \\
\text { 㧊 }\end{array}$ & 18.7 & 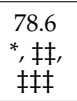 & 11.1 & $\begin{array}{c}80.6 \\
\ddagger \text { 㧊 }\end{array}$ & 20.8 & $\begin{array}{l}77.6 \\
\ddagger \ddagger \ddagger\end{array}$ & 16.8 & $\begin{array}{l}47.8 \\
\ddagger, \ddagger \ddagger\end{array}$ & 19.0 & 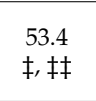 & 24.2 & 2.640 & 0.073 & 0.021 \\
\hline HF (n.u.) & 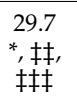 & 18.6 & 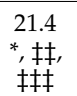 & 11.1 & $\begin{array}{c}29.7 \\
\ddagger ， \ddagger \ddagger\end{array}$ & 18.6 & $\begin{array}{l}22.1 \\
\text { 㧊 }\end{array}$ & 16.5 & $\begin{array}{l}52.3 \\
\ddagger, \ddagger \ddagger\end{array}$ & 18.8 & $\begin{array}{l}46.0 \\
\ddagger, \ddagger \ddagger\end{array}$ & 23.8 & 2.782 & 0.064 & 0.022 \\
\hline
\end{tabular}


Table 2. Cont.

\begin{tabular}{|c|c|c|c|c|c|c|c|c|c|c|c|c|c|c|c|}
\hline & \multicolumn{4}{|c|}{ Basal Test } & \multicolumn{4}{|c|}{$50 \mathrm{~m}$ Test } & \multicolumn{4}{|c|}{$400 \mathrm{~m}$ Test } & \multirow{2}{*}{\multicolumn{3}{|c|}{ Mask and Test Effect }} \\
\hline & \multicolumn{2}{|c|}{ No Mask } & \multicolumn{2}{|c|}{ Mask } & \multicolumn{2}{|c|}{ No Mask } & \multicolumn{2}{|c|}{ Mask } & \multicolumn{2}{|c|}{ No Mask } & \multicolumn{2}{|c|}{ Mask } & & & \\
\hline & $\mathbf{M}$ & SD & $\mathbf{M}$ & SD & $\mathbf{M}$ & SD & $\mathbf{M}$ & SD & $\mathbf{M}$ & SD & $\mathbf{M}$ & SD & $\mathbf{F}$ & $p$ & $\eta^{2}$ \\
\hline SD1 (ms) & $\begin{array}{c}16.3 \\
\ddagger \ddagger \\
\ddagger \ddagger \ddagger\end{array}$ & 4.54 & $\begin{array}{c}15.0 \\
\ddagger \ddagger \\
\ddagger \ddagger \ddagger\end{array}$ & 4.22 & $\begin{array}{l}6.89 \\
*, \ddagger\end{array}$ & 4.56 & $\begin{array}{l}9.02 \\
*, \ddagger \\
\ddagger \neq \ddagger\end{array}$ & 6.03 & $\begin{array}{c}5.26 \\
\ddagger\end{array}$ & 3.42 & $\begin{array}{l}5.90 \\
\ddagger, \ddagger \ddagger\end{array}$ & 3.61 & 4.119 & 0.017 & 0.033 \\
\hline $\mathrm{SD} 2(\mathrm{~ms})$ & 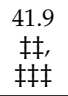 & 14.7 & 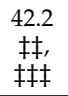 & 9.49 & 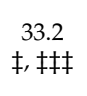 & 23.2 & $\begin{array}{c}31.8 \\
\ddagger\end{array}$ & 20.6 & $\begin{array}{l}10.2 \\
\ddagger ， \ddagger \ddagger\end{array}$ & 7.59 & $\begin{array}{l}12.4 \\
\ddagger ， \ddagger \ddagger\end{array}$ & 8.67 & 0.436 & 0.612 & 0.004 \\
\hline
\end{tabular}

M: Mean. SD: Standard Deviation. F: Fisher-Snedecor test. $\eta^{2}$ : Partial eta squared. SDNN: Standard deviation of normal-to-normal R-R intervals. RMSSD: Square root of the mean of the sum of the squared differences between adjacent normal R-R intervals. pNN50: The percentage of differences between R-R intervals higher than 50 ms. LF: Low frequency. HF: High frequency. n.u.: Normalised unit. SD1: Poincaré Plot index of instantaneous recording of the variability. SD2: Poincaré plot index of overall variability. $\ddagger$ Difference with basal test

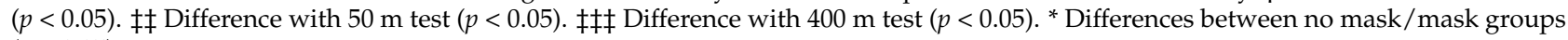
$(p<0.05)$.

\section{Discussion}

The present study aimed to analyze the effect of surgical mask use on the anaerobic running performance of athletes. The initial hypothesis was confirmed, since there was a decrease of anaerobic running performance while wearing a surgical mask.

Results suggested that wearing a surgical mask negatively affected anaerobic running performance, since there was a time increase of $12.51 \%$ on $50 \mathrm{~m}$ and $19.09 \%$ on $400 \mathrm{~m}$ test. This loss of performance has been attributed by authors to a metabolic shift and a decrease in muscle efficiency, a consequence of impaired autonomic stability, lower cardiac fitness and muscle blood supply [8]. However, other authors attributed the loss of performance to the discomfort associated with mask-wearing, higher ratings of dyspnea and lower blood oxygen saturation, showing a $14 \%$ reduction in exercise time and $29 \%$ decrease in $\mathrm{VO}_{2}$ max after maximal treadmill effort with surgical mask [24]. Our data support both studies, and are consistent with the lower blood oxygen saturation and greater values of RPE found in the present study after both tests.

Interestingly, blood glucose levels were higher in participants when wearing surgical masks after the $400 \mathrm{~m}$ test, but not after the $50 \mathrm{~m}$. In short anaerobic efforts, like the $50 \mathrm{~m}$ test, the organism obtains energy from phosphocreatine, which is used as the principal energy substrate, followed by the use of glucose when not highly active [25], explaining the lack of differences of glucose values in this test between the use and no use of mask. However, in the $400 \mathrm{~m}$ test, the mobilization of glucose is higher than in the $50 \mathrm{~m}$ test, the large metabolic demands, and the increased fermentation of glucose to respond to the high energy demand [26] explains the higher glucose value in this $400 \mathrm{~m}$ test than in the 50 m test.

The higher blood lactate value after the test when athletes used a mask may be due to a higher activation of the anaerobic lactic metabolism. As the oxygen supply to the cell is lower due to the re-inhalation of $\mathrm{CO}_{2}$ due to the use of the mask, the activation of aerobic metabolism is less, allowing a greater stimulus to produce energy by the lactic anaerobic metabolic pathways [27]. Which stimulates the mobilization of organic glucose to reach the active muscle cell and be consumed as an energy source. Contrary to our results, previous authors found no differences with and without mask on blood lactate values in a continuous cycling exercise [28] or steady state exercise [15]. The intensity of the activity performed in these studies was lower than in the actual study, close to the anerobic threshold $(\approx 4.2 \mathrm{mmol})$, thus, the contribution of anaerobic metabolism for this activity is lower and lactate concentration is more resistant to modification.

Rating of perceived exertion showed values close to maximum after the $400 \mathrm{~m}$ [29], being higher with the use of surgical mask. Authors suggested that the increased breathing resistance, heat, tightness, and overall discomfort while wearing masks, are items that increase subjective perception of effort, which is even greater when wearing an FP2/KN95 mask [27]. Furthermore, increases of more than $60 \%$ in RPE have been reported in resis- 
tance training efforts while wearing a mask [30]. We also found a significantly higher subjective perceived stress using the mask. It is feasible, that the masks negatively impact the dynamics of perception and effort, especially during demanding high intensity exercises [24], suggesting that the associated perceived effort [31] and stress [32] are important key reasons for the observed impairment of physical performance.

Regarding blood oxygen saturation, athletes with surgical mask presented lower values in both tests $(50 \mathrm{~m}$ and $400 \mathrm{~m}$ ). This lower blood oxygen saturation would be expected due to increased partial pressure of $\mathrm{CO}_{2}$ at high exercise intensity, increased tidal volume, and an inadequate oxygen and carbon dioxide exchange due re-breathing enriching inhaled air with $\mathrm{CO}_{2}$ [8]. Contrary to our results, authors did not find a blood oxygen saturation decrease with surgical masks, either during extenuated [33], vigorous [11] or steady exercise [34]. However, a key factor explaining the differences lies in the intensity and level of previous training. The authors chose a sample of subjects performing at their maximum in cycloergometer [11] until extenuation, at around $2.6 \mathrm{~W} / \mathrm{kg}$, values which suggest poorly physically active subjects, not athletes [35]. Furthermore, a recent review also suggests no blood oxygen saturation changes with the use of a surgical mask while exercising [12]. Yet, none of the studies included in the review were carried out at mediumlight physical intensity or with an athlete population. However, our results would be in line with previous hypotheses and studies on trained athletes to extenuation [8].

According to heart rate values, no differences were found between wearing and not wearing surgical mask. This response was previously seen in smaller cohorts that found surgical facemasks cause statistically insignificant [36] or clinically insignificant increases on heart rate values [37], at medium light intensity [12], during steady exercise [15], and even while wearing an FFP2/KN95 [27]. However, participants who wore a mask presented a decrease in heart rate variability, by means of higher sympathetic modulation in both tests, according the lower RMSSD, pNN50 and higher SD1 values observed. It may be explained as a result of an increased stress response. Authors described that while wearing surgical mask, there is impaired thermoregulation, discomfort, and increased hypoxia due to $\mathrm{CO}_{2}$ re-inhalation, which may lead to impaired autonomic modulation [38]. The higher rating of perceived exertion and subjective perceived stress while using a mask in both tests would reinforce this hypothesis. This accords with previous studies which found lower RMSSD and HF values, higher LF values [32], and a reduction of $80 \%$ on SDNN values [39]. Knowing the impact of short anaerobic tests on autonomic modulation, future research should focus on aerobic tests. Since the impact on autonomic modulation could be much greater, forcing coaches to take greater care and caution when planning training loads.

\section{Limitations of the Study}

One of the limitations of the present research was the low sample size, but the limitations, restrictions, and COVID-19 health protocols precluded recruitment of a larger sample. The lack of control for stress hormones such as cortisol or alpha amylase due to a lack of funding constituted another limitation.

\section{Practical Applications}

Higher levels of blood lactate and lower blood oxygen saturation require an adaptation of the athlete's rest and recovery periods to the acute workload. Also, the higher levels of sympathetic activation makes the acute and chronic control of the autonomic modulation essential for an efficient training periodization. Finally, the use of acid Buffers such as bicarbonate or sodium citrate would be a recommended ergogenic strategy. This information must be taken into account in physical activities as well as in physical activity lessons [40-42]. 


\section{Future Research}

We propose analysis of the effect of FFP2/KN95 masks on athletic performance as a subject for future research. We also suggest analysis of the effect of mask use on cortical arousal and athletic performance.

\section{Conclusions}

The use of surgical mask increased the blood lactate concentration, sympathetic autonomic modulation, rated of perceived exertion and perceived stress and decreased blood oxygen saturation in 50 and $400 \mathrm{~m}$ maximal running tests. Athletes and trainers should be aware of the effect of surgical masks as they continue to exercise safely during the global pandemic to keep up with their performance program.

Author Contributions: Conceptualization, V.J.C.-S. Formal analysis, A.B.-S.; Investigation; Writingoriginal draft; Writing - review \& editing - All authors. All authors have read and agreed to the published version of the manuscript.

Funding: This research received no external funding.

Institutional Review Board Statement: Ethics approval code CIPI/18/074.

Informed Consent Statement: Informed consent was obtained from all subjects involved in the study.

Data Availability Statement: All the data are in the manuscript.

Acknowledgments: We would like to acknowledge the predoctoral and undergraduate students who actively participated in the present study.

Conflicts of Interest: The authors declare no conflict of interest.

\section{References}

1. Helmy, Y.A.; Fawzy, M.; Elaswad, A.; Sobieh, A.; Kenney, S.P.; Shehata, A.A. The COVID-19 pandemic: A comprehensive review of taxonomy, genetics, epidemiology, diagnosis, treatment, and control. J. Clin. Med. 2020, 9, 1225. [CrossRef]

2. Senatore, V.; Zarra, T.; Buonerba, A.; Choo, K.H.; Hasan, S.W.; Korshin, G.; Li, C.W.; Ksibi, M.; Belgiorno, V.; Naddeo, V. Indoor versus outdoor transmission of SARS-COV-2: Environmental factors in virus spread and underestimated sources of risk. EuroMediterr. J. Environ. Integr. 2021, 6, 30. [CrossRef]

3. Pillay, L.; Janse van Rensburg, D.C.C.; Jansen van Rensburg, A.; Ramagole, D.A.; Holtzhausen, L.; Dijkstra, H.P.; Cronje, T. Nowhere to hide: The significant impact of coronavirus disease 2019 (COVID-19) measures on elite and semi-elite South African athletes. J. Sci. Med. Sport 2020, 23, 670-679. [CrossRef]

4. Clemente-Suárez, V.J.; Fuentes-García, J.P.; de la Vega Marcos, R.; Martínez Patiño, M.J. Modulators of the Personal and Professional Threat Perception of Olympic Athletes in the Actual COVID-19 Crisis. Front. Psychol. 2020, 11, 1985. [CrossRef]

5. Fuentes-García, J.P.; Martínez Patiño, M.J.; Villafaina, S.; Clemente-Suárez, V.J. The Effect of COVID-19 Confinement in Behavioral, Psychological, and Training Patterns of Chess Players. Front. Psychol. 2020, 11, 1812. [CrossRef]

6. Schinke, R.; Papaioannou, A.; Henriksen, K.; Si, G.; Zhang, L.; Haberl, P. Sport psychology services to high performance athletes during COVID-19. Int. J. Sport Exerc. Psychol. 2020, 18, 269-272. [CrossRef]

7. Flecha, S.S.; Pitta, N.M. Efectos por Uso Prolongado del EPI en Profesionales de Enfermería ante COVID 19: Hospitales de Contingencia Respiratoria; Academic Discl., 2020; Volume 1, pp. 24-39. Available online: https:/ / revistascientificas.una.py / ojs/index.php/ rfenob/article/view/135/109 (accessed on 14 July 2021).

8. Chandrasekaran, B.; Fernandes, S. “Exercise with facemask; Are we handling a devil's sword?"-A physiological hypothesis. Med. Hypotheses 2020, 144, 110002. [CrossRef]

9. Smith, C.L.; Whitelaw, J.L.; Davies, B. Carbon dioxide rebreathing in respiratory protective devices: Influence of speech and work rate in full-face masks. Ergonomics 2013, 56, 781-790. [CrossRef]

10. Melnikov, V.N.; Divert, V.E.; Komlyagina, T.G.; Consedine, N.S.; Krivoschekov, S.G. Baseline values of cardiovascular and respiratory parameters predict response to acute hypoxia in young healthy men. Physiol. Res. 2017, 66, 467-479. [CrossRef] [PubMed]

11. Shaw, K.; Butcher, S.; Ko, J.; Zello, G.A.; Chilibeck, P.D. Wearing of Cloth or Disposable Surgical Face Masks has no Effect on Vigorous Exercise Performance in Healthy Individuals. Int. J. Environ. Res. Public Health 2020, 17, 8110. [CrossRef]

12. Shaw, K.; Zello, G.A.; Butcher, S.; Ko, J.; Bertrand, L.; Chilibeck, P.D. The Impact of Face Masks on Performance and Physiological Outcomes during Exercise: A Systematic Review and Meta-analysis. Appl. Physiol. Nutr. Metab. 2021. [CrossRef]

13. Goh, D.Y.T.; Mun, M.W.; Lee, W.L.J.; Teoh, O.H.; Rajgor, D.D. A randomised clinical trial to evaluate the safety, fit, comfort of a novel N95 mask in children. Sci. Rep. 2019, 9, 18952. [CrossRef] 
14. Kim, J.H.; Benson, S.M.; Roberge, R.J. Pulmonary and heart rate responses to wearing N95 filtering facepiece respirators. Am. J. Infect. Control 2013, 41, 24-27. [CrossRef] [PubMed]

15. Lässing, J.; Falz, R.; Pökel, C.; Fikenzer, S.; Laufs, U.; Schulze, A.; Hölldobler, N.; Rüdrich, P.; Busse, M. Effects of surgical face masks on cardiopulmonary parameters during steady state exercise. Sci. Rep. 2020, 10, 22363. [CrossRef] [PubMed]

16. Shein, S.L.; Whitticar, S.; Mascho, K.K.; Pace, E.; Speicher, R.; Deakins, K. The effects of wearing facemasks on oxygenation and ventilation at rest and during physical activity. PLoS ONE 2021, 16, e0247414. [CrossRef] [PubMed]

17. Wong, A.Y.; Ling, S.K.; Louie, L.H.; Law, G.Y.; So, R.C.; Lee, D.C.; Yau, F.C.; Yung, P.S. Impact of the COVID-19 pandemic on sports and exercise. Asia Pac. J. Sports Med. Arthrosc. Rehabil. Technol. 2020, 22, 39-44. [CrossRef]

18. Clemente-Suárez, V.J.; Ramos-Campo, D.J. Effectiveness of reverse vs. traditional linear training periodization in triathlon. Int. J. Environ. Res. Public Health 2019, 16, 2807. [CrossRef]

19. Tornero-Aguilera, J.F.; Pelarigo, J.G.; Clemente-Suárez, V.J. Psychophysiological Intervention to Improve Preparedness in Military Special Operations Forces. Aerosp. Med. Hum. Perform. 2019, 90, 953-958. [CrossRef]

20. Borg, G. Borg's Perceived Exertion and Pain Scales; Human Kinetics: Champaign, IL, USA, 1998.

21. Tornero-Aguilera, J.F.; Robles-Pérez, J.J.; Clemente-Suárez, V.J. Could Combat Stress Affect Journalists' News Reporting? A Psychophysiological Response. Appl. Psychophysiol. Biofeedback 2020, 45, 231-239. [CrossRef]

22. Beltrán-Velasco, A.I.; Sánchez-Conde, P.; Ramos-Campo, D.J.; Clemente-Suárez, V.J. Monitorization of Autonomic Stress Response of Nurse Students in Hospital Clinical Simulation. BioMed Res. Int. 2021, 2021, 6641425. [CrossRef] [PubMed]

23. Shaffer, F.; Ginsberg, J.P. An Overview of Heart Rate Variability Metrics and Norms. Front. Public Health 2017, 5, 258. [CrossRef]

24. Driver, S.; Reynolds, M.; Brown, K.; Vingren, J.L.; Hill, D.W.; Bennett, M.; Gilliland, T.; McShan, E.; Callender, L.; Reynolds, E.; et al. Effects of wearing a cloth face mask on performance, physiological and perceptual responses during a graded treadmill running exercise test. Br. J. Sports Med. 2021. [CrossRef]

25. Scott, C. Misconceptions about Aerobic and Anaerobic Energy Expenditure. J. Int. Soc. Sports Nutr. 2005, 2, 32-37. [CrossRef]

26. Hirvonen, J.; Nummela, A.; Rusko, H.; Rehunen, S.; Härkönen, M. Fatigue and changes of ATP, creatine phosphate, and lactate during the 400-m sprint. Can. J. Sport Sci. 1992,17, 141-144. [PubMed]

27. Fikenzer, S.; Uhe, T.; Lavall, D.; Rudolph, U.; Falz, R.; Busse, M.; Hepp, P.; Laufs, U. Effects of surgical and FFP2/N95 face masks on cardiopulmonary exercise capacity. Clin. Res. Cardiol. 2020, 109, 1522-1530. [CrossRef]

28. Barbieri, J.F.; Gáspari, A.F.; Teodoro, C.L.; Motta, L.; Castaño, L.A.A.; Bertuzzi, R.; Bernades, C.F.; Chacon-Mikahil, M.P.T.; de Moraes, A.C. The effect of an airflow restriction mask (ARM) on metabolic, ventilatory, and electromyographic responses to continuous cycling exercise. PLoS ONE 2020, 15, e0237010. [CrossRef]

29. Williams, N. The Borg rating of perceived exertion (RPE) scale. Occup. Med. 2017, 67, 404-405. [CrossRef]

30. Motoyama, Y.L.; Joel, G.B.; Pereira, P.E.; Esteves, G.J.; Azevedo, P.H. Airflow-restricting mask reduces acute performance in resistance exercise. Sports 2016, 4, 46. [CrossRef]

31. Hopkins, S.R.; Dominelli, P.B.; Davis, C.K.; Guenette, J.A.; Luks, A.M.; Molgat-Seon, Y.; Sá, R.C.; Sheel, A.W.; Swenson, E.R.; Stickland, M.K. Face Masks and the Cardiorespiratory Response to Physical Activity in Health and Disease. Ann. Am. Thorac. Soc. 2021, 18, 399-407. [CrossRef] [PubMed]

32. Tornero-Aguilera, J.F.; Clemente-Suárez, V.J. Cognitive and psychophysiological impact of surgical mask use during university lessons. Physiol. Behav. 2021, 234, 113342. [CrossRef]

33. Mapelli, M.; Salvioni, E.; De Martino, F.; Mattavelli, I.; Gugliandolo, P.; Vignati, C.; Farina, S.; Palermo, P.; Campodonico, J.; Maragna, R.; et al. "You can leave your mask on": Effects on cardiopulmonary parameters of different airway protection masks at rest and during maximal exercise. Eur. Respir. J. 2021. [CrossRef] [PubMed]

34. Doherty, C.; Mann, L.; Angus, S.A.; Chan, J.; Molgat-Seon, Y.; Dominelli, P.B. Impact of wearing a surgical and cloth mask during cycle exercise. Appl. Physiol. Nutr. Metab. 2021, 46. [CrossRef]

35. Gardner, S.A.; Martin, T.D.; Barras, M.; Jenkins, G.D.; Hahn, G.A. Power output demands of elite track sprint cycling. Int. J. Perform. Anal. Sport 2005, 5, 149-154. [CrossRef]

36. Roberge, R.J.; Coca, A.; Williams, W.J.; Palmiero, A.J.; Powell, J.B. Surgical mask placement over N95 filtering facepiece respirators: Physiological effects on healthcare workers. Respirology 2010, 15, 516-521. [CrossRef]

37. Roberge, R.J.; Kim, J.H.; Benson, S.M. Absence of consequential changes in physiological, thermal and subjective responses from wearing a surgical mask. Respir. Physiol. Neurobiol. 2012, 181, 29-35. [CrossRef] [PubMed]

38. Rosner, E. Adverse effects of prolonged mask use among health care professionals during COVID-19. J. Infect. Dis. Epidemiol. 2020, 6, 130 .

39. Tian, Z.; Kim, B.Y.; Bae, M.J. A study on the effect of wearing masks on stress response. Memory 2020, 8, 12. [CrossRef]

40. Rodriguez-Besteiro, S.; Tornero-Aguilera, J.F.; Fernández-Lucas, J.; Clemente-Suárez, V.J. Gender Differences in the COVID-19 Pandemic Risk Perception, Psychology, and Behaviors of Spanish University Students. Int. J. Environ. Res. Public Health 2021, 18, 3908. [CrossRef] [PubMed]

41. Tornero-Aguilera, J.F.; Rubio-Zarapuz, A.; Clemente-Suárez, V.J. Implications of surgical mask use in physical education lessons. Physiol. Behav. 2021, 239, 113513. [CrossRef]

42. Clemente-Suárez, V.J.; Navarro-Jiménez, E.; Moreno-Luna, L.; Saavedra-Serrano, M.C.; Jimenez, M.; Simón, J.A.; Tornero-Aguilera, J.F. The Impact of the COVID-19 Pandemic on Social, Health, and Economy. Sustainability 2021, 13, 6314. [CrossRef] 